\title{
La Responsabilidad Social Territorial (RST) como enfoque para resignificar el estudio de las Prácticas de Responsabilidad Social de las Organizaciones (RSO)
}

\author{
ERnesto Valdés Serrano* \\ Luis Fernando Moreno Garzón ** \\ Norma Lucía Bonilla Londoño*** \\ Colombia
}

\section{Resumen}

El presente artículo hace una exploración teórica del concepto de Responsabilidad Social Territorial (RST) como eje para asumir el estudio de las prácticas de Responsabilidad Social de las Organizaciones (RSO) con un impacto sostenible en el lugar donde operan.

\section{Introducción}

El Grupo de Investigación en Responsabilidad Social y Ambiental (GIRSA), mediante el proyecto "Responsabilidad social y redes socio

* Profesor Universidad Piloto de Colombia. Contacto: ernesto-valdes@unipiloto.edu.co

** Profesor Universidad Santo Tomás. Contacto: luismoreno@usantotomas.edu. co

***Profesora Universidad Piloto de Colombia. Contacto: norma-bonilla@unipiloto.edu.co 
institucionales en pymes en Bogotá Región”, se ha centrado entre los años 2015 y 2016 en formular desde un nuevo enfoque la manera de estudiar las prácticas de responsabilidad de las organizaciones para agenciar el desarrollo sostenible en el territorio. El abordaje convencional de la Responsabilidad Social (Rs) de las organizaciones en Colombia ha sido dominante en pensar que la resolución de las necesidades de los grupos en estado más vulnerable y el cuidado del medio ambiente tienen como eje central la empresa y su relación con sus grupos de interés o stakeholders; pero, contrariamente, al adoptar una perspectiva de desarrollo integral (articulación de lo económico, con lo social y lo ambiental), lo cual implica a la vez la construcción de lo público y la formación de ciudadanías (o de sujetos activos en pro de sus derechos) en un territorio, se plantea que toda organización (incluyendo la empresarial) es un actor relevante, del cual se esperan acciones corresponsables en función de buscar un desarrollo territorial sostenible (Lozano, 2009). ${ }^{1}$

Por lo tanto, desde este punto de vista, el propósito que emerge para la construcción de conocimiento sobre la Rs se centra en la pregunta ¿cuáles son las potencialidades de las organizaciones para contribuir a estructurar lo público con gobernanza participativa en el marco de la Responsabilidad Social Territorial? Esto con el propósito de identificar las potencialidades de las organizaciones para contribuir a estructurar lo público con gobernanza participativa, en torno a promover una Responsabilidad Social Territorial (RST), concepto que finalmente convoca a la corresponsabilidad de todos los actores (organizacionales) — como

1 Girsa ha asumido como preocupación el estudio de la Rs tanto en pequeñas y medianas empresas (pymes), siguiendo la definición de estas unidades económicas en el contexto colombiano que hace la Ley 905 de 2004, artículo 2..$^{\circ}$ para su promoción (conforme a parámetros de número de trabajadores y valor de activos), como en aquellas organizaciones no gubernamentales sin ánimo de lucro - llamado también tercer sector o de economía social— que conforman parte importante del sector social y de servicios públicos en la región (Grosso Rincón, 2013). Se ha considerado especialmente que las pymes participan en la economía colombiana y en particular en la bogotana de manera sobresaliente en términos de empleo formal e ingresos, lo cual sugiere a la vez un potencial para agenciar el desarrollo sostenible de la región (Zuleta, 2011, pp. 168-176). 
Estado, empresas y el denominado "tercer sector"- para proyectar y materializar un territorio con desarrollo sostenible.

Esta postura requiere, para elaborar un reconocimiento sobre prácticas de Rso, el enfoque de Zemelman (2012, p. 56), que propone adoptar como forma de razonamiento un "pensar epistemológico" frente a un "pensar teórico" (que limita el pensamiento a los contenidos de las proposiciones establecidas por una disciplina) para la construcción de un conocimiento pertinente y situado históricamente.

En esta perspectiva el problema epistemológico, no consiste tanto en buscar una mejor fundamentación del conocimiento como en potenciar la facultad de reconocimiento de lo dándose; esto es, en vislumbrar horizontes posibles de conocimiento y/o acciones para sensibilizarnos ante el momento histórico y también ante estructuras teóricas y valóricas que se expresan en particulares organizaciones conceptuales. (Zemelman, 2012, p. 30)

\section{Marco teórico}

Este tema de la RST está muy relacionado con el concepto de desarrollo sostenible (DS) y la posibilidad que ofrece para enfocar las características, alcances y potencialidades de las prácticas de Rs en actores concretos del territorio (en nuestro caso, Bogotá región), como paso necesario para orientar la construcción de nuevo conocimiento en pro del mejoramiento, fortalecimiento o transformación de las acciones organizacionales. Cabe anotar que la responsabilidad social de las organizaciones se puede considerar como una manifestación ética que contribuye al desarrollo sostenible y, como parte de eso, al fomento de lo público en un territorio, considerando a los derechos de las personas como un objetivo de la actividad económica, social y ambiental. ${ }^{2}$

2 Cuando se plantea la idea de manifestación ética de las organizaciones, siguiendo a Manrique, H., Lopera et al. (2016, pp. 96 y 97), se distinguen sujetos singulares (como las personas) respecto a sujetos plurales (como las organizaciones). Según estos autores, se entiende "un sujeto como una organización 
Con esta premisa, un enfoque de partida y eje de la Rso es el concepto de Desarrollo Sostenible (DS), retomado del informe Brundtland (1987), ${ }^{3}$ el cual implica entender que los países por medio de sus políticas públicas buscarán satisfacer las necesidades del presente sin comprometer las necesidades de las futuras generaciones, abarcando con ello la sustentabilidad ecológica y un marco que integre en el desarrollo lo social y lo económico para superar los grandes problemas de la humanidad.

Tradicionalmente las políticas públicas se dirigen a generar renta y riqueza económica en un territorio y su población; pero, siguiendo a Sen (2000), esto no es razón suficiente para concebir el desarrollo; “el desarrollo tiene que ocuparse más de mejorar la vida que llevamos y las libertades de que disfrutamos" (Sen, 2000, p. 31). Específicamente debe propiciar oportunidades para que las personas desarrollen sus capacidades básicas y ejerzan la libertad de escoger el tipo de vida que más valoren. Y las capacidades que una sociedad ayudará a propiciar en las personas, dependerá de las finalidades que se proponga resolver, respondiendo a "la noción de dignidad humana y de vida humana digna" (Nussbaum, 2012, p. 49), lo cual implica un reconocimiento de que estas como ciudadanos y sujetos de derechos también son agentes de cambios en lo económico, social y político, entre otros campos (Sen, 2000).

Complementariamente, bajo la perspectiva del desarrollo a escala humana (Max- Neef, 1986), la participación de los diferentes actores sociales para crear un orden político que garantice una cultura democrática es una base importante para la resolución de los

porque es la encarnación de una serie de instituciones, es decir, de discursos fundantes en torno a los cuales existen acuerdos tácitos o explícitos que estructura la sociedad. Y también se planteó que la organización puede tomarse como un sujeto porque es un ente racional que actúa, genera efectos en el ambiente a partir de una estructura particular que ha sido producida en un proceso de estructuración con vicisitudes singulares”.

3 Informe elaborado para la onU, por una comisión encabezada por la doctora Gro Harlem Brundtland. Originalmente se llamó "Nuestro Futuro Común" (Our Common Future). Ver al respecto Naciones Unidas (1987). 
problemas que se preservan en el denominado Tercer Mundo. No es, por tanto, prioridad de esta perspectiva definir qué deben hacer los Estados, sino más bien identificar la relevancia de que la sociedad civil se pueda hacer cargo de definir vías posibles de resolución de sus problemas. En esta dirección, se sustenta que "el desarrollo se refiere a las personas y no a los objetos" (Max-Neef, 1986, p. 25), siendo necesario diferenciar entre necesidades a satisfacer y los satisfactores a elegir para construir "una política de desarrollo auténticamente humanista" (p. 34) y sujeta a la vez a un movimiento incesante de las culturas. Todo esto implica entender que, desde Max-Neef (1986), no hay una sola posibilidad de desarrollo y que, contrariamente, se debe considerar la dimensión subjetiva en la elección de satisfactores de las necesidades humanas para abrir el paso a proyectos de vida diversos o que al menos eviten las patologías colectivas derivadas de la privación y la frustración.

En esto se entendería que la construcción de lo público y de todo aquello que propicie el bien común en un territorio enfocando el desarrollo hacia lo sostenible —en lo cual pueden ser inherentes las disputas, consensos y construcción de hegemonías, siguiendo a Gramsci (Retamozo, 2006) - demandaría de condiciones políticas para ejercicios de gobernanza democrática ${ }^{4}$ entre los diferentes actores que lo constituyen, tales como las organizaciones empresariales, del sector público y sociales o de la sociedad civil, que faciliten nuevas formas de decisión horizontales y cooperativas para la formulación, aplicación y evaluación de políticas públicas. Por consiguiente, la participación de la sociedad civil para resolver los problemas que considere relevantes, o en función de intereses colectivos, tendría como base la construcción de gobernanza en el territorio correspondiente y no simplemente esperar la emisión de políticas públicas provenientes del Estado.

\section{Metodología}

4 Ver al respecto Torres Carrillo (2015, pp. 225-238) y Jiménez et al. (2007, pp. 82-96). 
El concepto de RST se adoptó como resultado de una investigación documental $^{5}$ — con apoyo del software Atlas.Ti, versión 6.1—, en la cual, partiendo de predefinir la RST y los conceptos de Responsabilidad Social y Empresa Ciudadana, se desarrolló un procedimiento analítico desde el que se transforman dichos conceptos en categorías como fuente de un conocimiento pertinente o situado histórica y culturalmente y con posibilidad de captar la potencialidad de la acción de los sujetos sociales, conforme a la dirección que buscan imprimirle en relación con un proyecto de territorio sostenible. ${ }^{6}$

\section{Resultados}

En este aparte se distinguen dos niveles de análisis para resolver el problema y objetivo inicialmente propuestos. Uno referido a delimitar el concepto de Responsabilidad Social Territorial (RST) y el otro a desplegar las subcategorías que se consideran esenciales para penetrar en los contextos organizacionales de interés (en Bogotá región), considerando estos como marcos culturales que son susceptibles de interpretar y contribuir a transformar en pro del Desarrollo Sostenible.

5 Uribe Roldán (2011, p. 196) define así la Investigación documental (ID): “Es en esencia el estudio metódico, sistemático y ordenado con objetivos bien definidos, de datos, documentos escritos, fuentes de información impresas, contenidos y referencias bibliográficas, los cuales una vez recopilados, clasificados, categorizados y analizados, sirven de base para la compresión del problema, la definición o redefinición de nuevos hechos o situaciones problémicas, la elaboración de hipótesis o la orientación a nuevas fuentes de investigación en la construcción de conocimiento".

6 La noción de territorio se entiende como bioespacio o lugar. Siguiendo a Fals Borda (2000, p. 9), "aparece como respuesta a procesos locales y regionales de desarrollo social, económico y político que vinculan actividades vitales de producción y reproducción con los recintos en que se ejecutan y de donde se derivan elementos de continuidad social y diversidad cultural. (...) En estos bioespacios se expresa y palpa la vida colectiva en su cotidianidad: la relación territorio-población-servicios es fundamental, y de allí depende mucho la convivencia, la prosperidad y la paz ciudadanas y el buen manejo que se dé a los recursos financieros que reciba”. 


\title{
¿Qué se entiende por RST?
}

\author{
Según Benítez, Campos y Vidal (2015, p. 4),
}

este concepto se enmarca en un área de investigación, aún incipiente, que se conoce como Responsabilidad Social Territorial (RST). No existe un uso consensuado del concepto de RST, las diferentes definiciones se centran en establecer qué caracteriza a un territorio que sea socialmente responsable.

Bajo esta premisa, y conforme al procedimiento analítico realizado mediante la sistematización documental, fue posible encontrar en la RST un vínculo de la responsabilidad social de las organizaciones con la preocupación del desarrollo territorial con enfoque sostenible, considerando como base de este la construcción de corresponsabilidad (o responsabilidad colectiva) entre los diversos actores que operan en él —apoyados en una visión y esfuerzos compartidos- para garantizar una formulación y aplicación democrática de políticas públicas por el fomento del bienestar común. A continuación se sintetizan los significados encontrados y procesados sobre la RST. $^{7}$

7 Información tomada parcialmente de documento de trabajo de los autores denominado: "Estudio de las prácticas de responsabilidad social de las organizaciones como campo de posibilidades para el desarrollo sostenible en el territorio de Bogotá región” (Valdés, Moreno y Bonilla, 2016, pp. 12-14). 
Tabla 1. Síntesis de sistematización documental de la categoría Responsabilidad Social Territorial

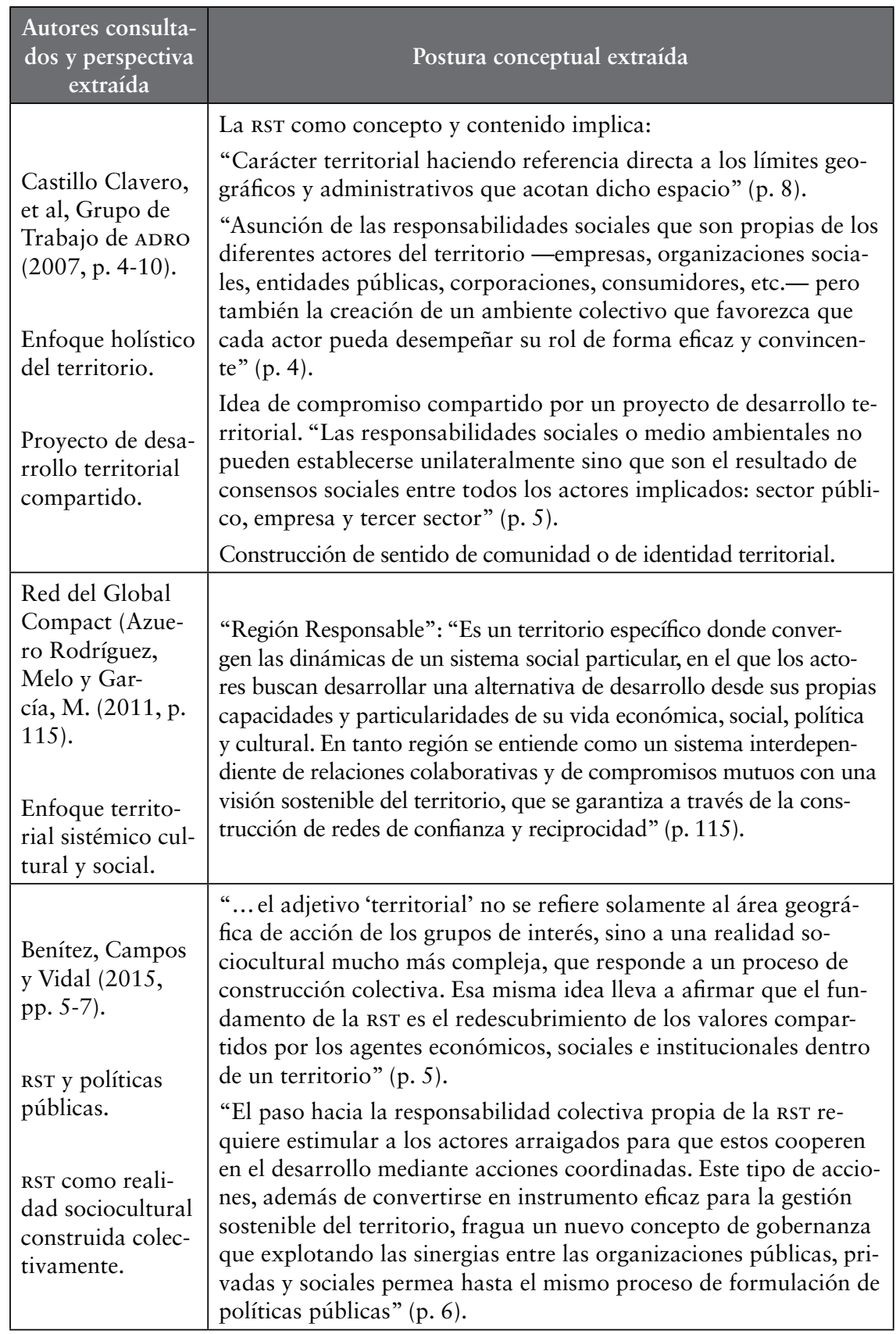

Fuente: elaboración de los autores tomada del documento de trabajo: "Estudio de las prácticas de responsabilidad social de las organizaciones como campo de posibilidades para el desarrollo sostenible en el territorio de Bogotá región” (Valdés, Moreno y Bonilla, 2016, pp. 11-13). 
Con base en esta síntesis y la categorización presentada en la anterior tabla, según los autores consultados, se destaca en la noción de RST lo siguiente: ${ }^{8}$

- Se entiende el territorio como un espacio posible de delimitar desde lo geográfico, administrativo, social, político y cultural, en el cual participan actores diversos según sus roles.

- Un enfoque integral de la Rs que implica a todos los actores de un territorio, para que articulen en sus actividades lo ambiental, social y económico.

- La posibilidad de construir una racionalidad convergente de todos los actores que componen el territorio para aplicar una visión sostenible, apoyados en procesos de gobernanza y forjando redes de confianza y reciprocidad.

- El reconocimiento de capacidades y singularidades de los actores en lo económico, social, cultural y político para construir y gestionar un proyecto de desarrollo compartido con enfoque sostenible.

La RST, por tanto, supone que los diferentes actores del territorio (entre esos, las organizaciones privadas) serían agentes corresponsables en las estructuras económicas, sociales y ambientales para construir un territorio sostenible, debido a su potencial de generación de valores compartidos (ejerciendo la Responsabilidad Social).

Esta corresponsabilidad se haría materializable bajo procesos de gobernanza participativa, entendiendo en esto que la función del Estado debe ir más allá de su función de gobernar, o no limitada a ejercer su autoridad y accionar mediante sus entidades gubernamentales, sino más bien emplear su función de gobierno bajo un enfoque sistémico y relacional en el que ejerza un papel asociativo y coordinador para aprovechar las sinergias de la sociedad civil para gestar políticas

8 Síntesis tomada parcialmente de documento de trabajo de los autores denominado: "Estudio de las prácticas de responsabilidad social de las organizaciones como campo de posibilidades para el desarrollo sostenible en el territorio de Bogotá región” (Valdés, Moreno y Bonilla, 2016, pp. 14-15). 
públicas. Esta perspectiva plantea a su vez la necesidad de pensar en una forma de articular los diversos agentes del desarrollo en el territorio, centrada en recoger sus iniciativas que ofrezcan respuestas tanto a sus intereses como a las demandas sociales o colectivas.

\section{Propuesta de subcategorías a indagar en las organizaciones en torno a la Responsabilidad Social Territorial (RST)}

Con esta delimitación de la RST, se definen a continuación los aspectos o subcategorías que serían más apropiadas o congruentes con el enfoque del DS, para indagar acerca de la aproximación a la RST de las organizaciones desde una perspectiva sociocultural. Se trata aquí de desagregar las categorías inicialmente delineadas en el anterior aparte en torno a la RST, para identificar en las organizaciones objeto de interés, las representaciones sociales de las personas que las constituyen con el fin de entender y comprender el abordaje de la realidad social desde su pensamiento práctico; ${ }^{9}$ en este caso, se trataría del conocimiento previo o representación acerca del contexto territorial que conciben relevante (o reconocible) y en el cual desarrollan su actividad misional. Igualmente, son subcategorías concebidas para realizar un acercamiento inicial al marco de valores que tienen estas organizaciones frente al territorio donde operan o que delimiten como relevante para su acción. Se distingue así lo siguiente: ${ }^{10}$

9 Siguiendo a Jodelet (1986, pp. 470-473), citado por Villarroel (2007, p. 440), las representaciones sociales son "imágenes que condensan un conjunto de significados; sistemas de referencia que nos permiten interpretar lo que nos sucede, e incluso, dar un sentido a lo inesperado; categorías que sirven para clasificar las circunstancias, los fenómenos y a los individuos con quienes tenemos algo que ver; teorías que permiten establecer hechos sobre ellos”.

10 Aspectos tomados parcialmente del documento de trabajo de los autores denominado: "Estudio de las prácticas de responsabilidad social de las organizaciones como campo de posibilidades para el desarrollo sostenible en el territorio de Bogotá región” (Valdés, Moreno y Bonilla, 2016, pp. 14 y 15). 
Identificación de la concepción de territorio con los actores relevantes donde opera la organización. Esto implica indagar:

- Delimitación del territorio y apreciación de problemas más relevantes y soluciones que están en tránsito o que se podrían concebir o impulsar allí.

- Delimitación del contexto de acción de la organización: Historia de la organización en el territorio y descripción de su misión (o función social) hacia la sociedad, cómo se delimita espacial y temporalmente.

- Comprensión que se tiene del contexto y del territorio donde concreta la organización su preocupación según la función social que cumple o busca desarrollar.

- Problemas más relevantes que la organización identifica y asume como prioridad contribuir a resolver en el territorio. Posibles perspectivas o dimensiones a indagar:

- Económica (empleo, generación de ingresos, acceso a mercados y competitividad, innovación).

- Bienestar social y oportunidades para el desarrollo humano (equidad social con base en el acceso a bienes colectivos).

- Cuidado del medio ambiente.

- Participación política o en gestión de asuntos públicos.

- Promoción de ciudadanía activa y desarrollo institucional a favor de grupos en mayores condiciones de vulnerabilidad.

- Identidad, capital social y desarrollo cultural.

- Ordenamiento del territorio o uso del espacio con determinados fines.

- Otras dimensiones.

- Relación con sus grupos de interés o stakeholders: Identificación y conocimiento de estos, construcción de confianza y desarrollo de redes. Relaciones de poder y antagonismos latentes o activos. - Identificación de actores más activos que se perciben en el territorio para desarrollarlo o solucionar los problemas enunciados o focalizados. 
- Actores del sector público.

- Actores del sector privado con ánimo de lucro.

- Organizaciones no gubernamentales o del tercer sector.

- Otros.

- Identificación de la apreciación de los desempeños del sector público, sector privado y tercer sector, respectivamente, para el desarrollo del territorio, en términos de:

- Capacidades que son destacables en estos actores (ejemplo: promover proyectos, toma de decisiones, aprendizaje e innovación, cooperación y colaboración con otros actores o formación de redes, entre otras).

- Recursos que despliegan para el desarrollo territorial (ejemplo: económicos, tecnológicos, humanos e información).

- Logros o resultados que se perciben en estos actores respecto a los requerimientos del territorio.

Proyecto (o modelo) de empresa u organización que se ha concebido (o se promueve en la práctica) conforme a su actividad económica específica y su papel frente a las problemáticas o necesidades que se perciben relevantes en el territorio. Esto se puede discernir por medio de la indagación de:

- Marco de valores que ayudan a interpretar y guiar su acción en el territorio. Qué papel se considera que desempeña (y debe desempeñar en el futuro) la organización en el territorio.

- Modo de proyectar o aplicar ese marco de valores en sus relaciones con cada uno de sus stakeholders. Lo anterior conforme a grupos de interés de mayor atención o prioridad en la gestión.

Impactos de la organización en el territorio.

Concepción de gobernanza, incluyendo la identificación de procesos de gobernanza en el territorio en función de promover su desarrollo. Se debe abarcar al respecto:

- Cómo se entiende la participación o promoción de agendas de trabajo o proyectos compartidos con otros actores en función de contribuir a resolver problemas del territorio. 
- Actores que más participan y actores que quizás no están incluidos y son necesarios para la toma de decisiones respecto a la construcción del bien común o de lo público.

- Formas que se percibe de organización-participación e integración a la gobernanza y para la aplicación de decisiones colectivas (por ejemplo: conformación y desarrollo de redes).

- Antagonismos y relaciones de poder que se percibe entre actores preocupados por el desarrollo del territorio y cómo se resuelven o procesan los conflictos.

- Impactos de procesos de gobernanza en el territorio.

Si no hay experiencias de gobernanza, sería preciso indagar por la apreciación de las condiciones en que se formulan, aplican y evalúan las políticas públicas y el papel (y peso específico) que se registra en esto de los distintos actores relevantes del territorio.

\section{Conclusiones}

Bajo el concepto de la RST se puede abrir el camino a reconocer lo territorial como entidad fundamental del DS y, con eso, la identificación de los actores concretos que pueden ser (o son) agentes del desarrollo, para finalmente - con apoyo de la investigación- producir orientaciones que contribuyan a encauzar, fortalecer o promover en las organizaciones visiones y capacidades para el desarrollo de prácticas más complejas o hacia la corresponsabilidad en pro del DS.

El estudio de las prácticas de Rs en las organizaciones implica indagar sobre sus aspectos axiológicos y culturales que serían la base para entender el sentido y dirección de estas prácticas y su potencial para promover la corresponsabilidad y la gobernanza democrática en función de un proyecto de desarrollo territorial. En este marco, el abordaje de las representaciones sociales de los actores de las organizaciones del territorio nos proporcionarán las categorías básicas que implican sus condiciones económicas, sociales, históricas y el sistema de sus creencias y valores. Esto posibilitará desplazarnos de un conocimiento centrado en el "ser" al "deber ser" a partir de un conocimiento 
socialmente elaborado y compartido en cada organización, teniendo una visión práctica y concurrente en la construcción de una realidad común frente a la RST.

Según Jodelet (1986), esta construcción se realiza y transmite a través del discurso de los individuos; un discurso donde lo familiar para un grupo de personas es expresado en su forma común de pensar que puede producir este objeto social, que en nuestro caso se establecería desde una visión compartida acerca del desarrollo territorial sostenible.

Con el despliegue del concepto de RST elaborando categorías que posibilitan identificar prácticas de RSO en el territorio de interés, se abre también el camino para establecer las concepciones, valores y experiencias de actores organizacionales concretos en relación con su compenetración o situación respecto a los problemas que identifican como más relevantes del territorio donde operan (asociado a lo que se entendería de interés público) y si disponen de potencialidades que faciliten el desarrollo de redes y procesos de gobernanza como base para agenciar la RST o la construcción de un "territorio socialmente responsable".

Por consiguiente, este nuevo enfoque dotaría a la actividad investigativa hacia la búsqueda de un conocimiento útil en función de plantear propuestas contextualizadas —en torno a una visión compartida de desarrollo territorial sostenible- para la transformación o mejoramiento de las prácticas de Rso, lo cual supone superar las posturas tradicionales en el estudio de la Rs que mantienen una centralidad en las empresas - para propiciar el Ds- o que se reducen a situar los progresos o las dificultades en estas prácticas bajo una dimensión descriptiva, prescriptiva o estrictamente crítica. 


\section{Referencias}

Araya Umaña, S. (2002). Las representaciones sociales. Ejes teóricos para su discusión [Online]. Cuadernos de Ciencias Sociales, 127. Facultad Latinoamericana de Ciencias Sociales (Flacso). Sede académica Costa Rica. Primera edición. Recuperado de http://unpan1.un.org/intradoc/groups/ public/documents/ICAP/UNPAN027076.pdf

Azuero Rodríguez, A., Melo, J. M. y García, M. (2011). Una presentación de la región socialmente responsable del Norte del Cauca. Cuadernos de Administración de La Facultad de Ciencias de La Administración de La Universidad Del Valle, 27(45), 109-121. Recuperado de http://www. scielo.org.co/pdf/cuadm/v27n45/v27n45a07.pdf

Benítez, C., Campos, M.L. y Vidal, J.M. (2015). Responsabilidad social territorial. Ejemplo de gobernanza innovadora y competitiva en Alcalá de Guadaíra. Revista Atlántica de Economía, 1(1). Recuperado de https:// dialnet.unirioja.es/servlet/articulo?codigo $=5318378$

Castillo Clavero, A. M., Abad Guerrero, I. M., Martínez Fernández, P. y Rastrollo Horrillo, M. Á. (2007). Grupo de trabajo de ADRO. Documento base sobre los territorios socialmente responsables. Recuperado de http:// www.empleo.gob.es/uafse/es/COP/redRetos/01.pdf

Congreso Nacional de la República de Colombia. Ley 905 de 2004. Por medio de la cual se modifica la Ley 590 de 2000 sobre promoción del desarrollo de la micro, pequeña y mediana empresa colombiana y se dictan otras disposiciones (12 de julio, 2004) Recuperado de http://www.alcaldiabogota.gov.co/sisjur/normas/Norma1.jsp?i=14501

Fals Borda, O. (2000). Acción y espacio. Autonomías en la nueva República. Bogotá: Tercer Mundo Editores-Iepri, Universidad Nacional.

Grosso Rincón, C. (2013). La economía social desde tres perspectivas: tercer sector, organizaciones no gubernamentales y entidades sin ánimo de lucro. Revista Tendencias \& Retos, 18(1), 143-158. Recuperado de https:// dialnet.unirioja.es/descarga/articulo/4929405.pdf;

Jiménez, W. G., Ramírez, C. y Roncancio, P. (2007). Gobernabilidad y gobernanza en la transformación de la acción pública. Propuesta teórica y estudio de caso. Bogotá: Escuela Superior de Administración Pública, EsAP.

Jodelet, D. (1986). La representación social: fenómenos, concepto y teoría. En Moscovici, S. (eds.), Psicología Social II. Barcelona: Paidós. 
Lozano, J. M. (2002). La empresa ciudadana un reto de innovación. Recuperado de http://itemsweb.esade.es/wi/research/iis/publicacions/La_Empresa_Ciudadana.pdf

Lozano, J. M. (2009). La empresa ciudadana como empresa responsable y sostenible. Madrid: Trotta S.A.

Manrique, H., Lopera, I., Pérez, J., Ramírez, V. y Henao, C. (2016). Clínica analitica de las organizaciones. Bogotá: Editorial San Pablo-Fondo Editorial Universidad Eafit.

Max-Neef, M., Elizalde, A. y Hopenhayn, M. (1986). Desarrollo a escala bumana. Una opción para el futuro. Santiago de Chile: Cepaur-Fundación Dag Hammrsk jold.

Naciones Unidas (1987). Informe de la Comisión Mundial sobre el Medio Ambiente y el Desarrollo. Recuperado de https://es.scribd.com/ doc/105305734/ONU-Informe-Brundtland-Ago-1987-Informe-de-la-Comision-Mundial-sobre-Medio-Ambiente-y-Desarrollo

Nussbaum, M. C. (2012). Crear capacidades. Propuesta para el desarrollo humano. España, Espasa Libros S.L.U.

Retamozo, M. (2006). Notas en torno a la dicotomía público-privado: una perspectiva política. Reflexión Política, 8(16), 26-35. Recuperado de http://www.redalyc.org/pdf/110/11001603.pdf

Sen, A. (2000). Desarrollo y libertad. Bogotá: Planeta Colombiana S.A. Tercera reimpresión, 2001.

Torres Carrillo. A. (2015). Acción colectiva, gestión territorial y gobernanza democrática en Bogotá. En A. Torres Carrillo y A. Torres Ruiz (comps.). (1. ${ }^{\text {ra }}$ ed.). Bogotá: Universidad Piloto de Colombia.

Uribe Roldán, J. (2011). La investigación documental y el estado del arte como estrategias de investigación en ciencias sociales. En P. Páramo (comp.), La investigación en Ciencias Sociales: estrategias de investigación (pp. 195-210). (1. ${ }^{\text {ra }}$ ed). Bogotá: Universidad Piloto de Colombia.

Valdés, E., Moreno, L. F. y Bonilla, N. (2016). Estudio de las prácticas de responsabilidad social de las organizaciones como campo de posibilidades para el desarrollo sostenible en el territorio de Bogotá región. Documento de Trabajo, Universidad Piloto de Colombia y Universidad Santo Tomás. Bogotá, Colombia.

Villarroel, G. E. (mayo-agosto, 2007). Las representaciones sociales: una nueva relación entre el individuo y la sociedad. Fermentum. Revista Venezolana de Sociología y Antropología, 17(49), 434-454. 
Zemelman, H. (2012). Los horizontes de la razón. Vol. II. Historia y necesidad de utopía. 3. ${ }^{\mathrm{ra}}$ ed. Barcelona: Anthropos Editorial.

Zuleta, L.A. (2011). "Políticas e instituciones de apoyo a las pymes en Colombia". Tomado de Apoyando a las pymes: políticas de fomento en América Latina y el Caribe. En C. Ferraro (comp.), Cepal, Naciones Unidas, 2011. Recuperado de http://repositorio.cepal.org/bitstream/ handle/11362/35359/S1100762_es.pdf 


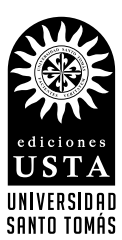

Esta obra se editó en Ediciones USTA,

Departamento Editorial de la Universidad Santo Tomás.

Se usó papel propalcote de 300 gramos para la carátula y papel bond beige de 70 gramos para páginas internas.

Tipografía Sabon LT Std.

Impreso por: Xpress. 